\title{
Associations of Dietary Patterns and Nutrients with Glycated Hemoglobin in Participants with and without Type 1 Diabetes
}

\author{
Arpita Basu 1,* Amy C. Alman ${ }^{2}$ and Janet K. Snell-Bergeon ${ }^{3}$ \\ 1 Department of Kinesiology and Nutrition Sciences, School of Integrated Health Sciences, University of \\ Nevada, Las Vegas, NV 89154, USA \\ 2 College of Public Health, University of South Florida, Tampa, FL 33612, USA; aalman@usf.edu \\ 3 Barbara Davis Center for Childhood Diabetes, Anschutz Medical Campus, University of Colorado, \\ Aurora, CO 80045, USA; janet.snell-bergeon@cuanschutz.edu \\ * Correspondence: Arpita.basu@unlv.edu; Tel.: +1-702-895-4576
}

Citation: Basu, A.; Alman, A.C.; Snell-Bergeon, J.K. Associations of Dietary Patterns and Nutrients with Glycated Hemoglobin in Participants with and without Type 1 Diabetes. Nutrients 2021, 13, 1035. https:// doi.org/10.3390/nu13031035

Academic Editor: Ornella Guardamagna

Received: 25 February 2021

Accepted: 21 March 2021

Published: 23 March 2021

Publisher's Note: MDPI stays neutral with regard to jurisdictional claims in published maps and institutional affiliations.

Copyright: (c) 2021 by the authors. Licensee MDPI, Basel, Switzerland. This article is an open access article distributed under the terms and conditions of the Creative Commons Attribution (CC BY) license (https:// creativecommons.org/licenses/by/ $4.0 /)$.

\begin{abstract}
Background: Diet has been associated with poor glycemic control in diabetes. Few studies have examined this association in people with type 1 diabetes (T1D), who are at a higher risk for cardiovascular disease than people without diabetes. Methods: We report data from cross-sectional and longitudinal analyses from a coronary artery calcification in type 1 diabetes (CACTI) study ( $n=1257$; T1D: $n=568$; non-diabetic controls: $n=689$ ) collected between the years 2000 and 2002. Participants completed a validated food frequency questionnaire, a physical examination, and biochemical analyses. Dietary patterns based on variations in food group intake were created with principal components analysis. Linear regression was used to examine the associations of dietary patterns, macronutrients, and food groups with $\mathrm{HbA} 1 \mathrm{c}$ in a model adjusted for relevant covariates and stratified by diabetes status. Results: Three dietary patterns were identified: "fruits, veggies, meats, cereal", "baked desserts" and "convenience foods and alcohol" patterns. At baseline, a higher intake of the "baked dessert" pattern was significantly associated with higher HbA1c in T1D at baseline as well at year 6 of the study when adjusted for age, sex, BMI, total calories, and diabetes duration. No such associations were observed in the case of non-diabetic controls. Dietary saturated fats and animal fats were also positively associated with $\mathrm{HbA} 1 \mathrm{c}$ in adults with T1D at baseline and/or at year 6. Conclusions: The habitual intake of a dietary pattern that is characterized by an increased intake of added sugar and saturated fats, such as in baked desserts, may increase risks of poor glycemic control in T1D.
\end{abstract}

Keywords: dietary patterns; baked desserts; type 1 diabetes; glycated hemoglobin

\section{Introduction}

The prevalence of diabetes mellitus has been increasing at an alarming rate in the US adult population [1], including type 1 diabetes (T1D), which carries a higher burden of cardiovascular disease (CVD) than is found in the general population [2]. T1D is an autoimmune condition characterized by pancreatic beta cell destruction and absolute insulin deficiency, and dietary measures remain a key for glycemic control and achieving glycated hemoglobin $\mathrm{HbA} 1 \mathrm{c} \leq 7.0 \%$ in the primary management of this disease [3]. The American Diabetes Association has increasingly emphasized the need for "healthful eating patterns" that contain a variety of nutrient-dense foods for optimal glycemic control, as well as in the management of obesity and dyslipidemia, which contribute to excess CVD risks in diabetes [4]. Despite several reported clinical trials on the optimal diet composition for the management of hyperglycemia in T1D, the results remain inconclusive in most cases. Dietary carbohydrates as a direct contributor to the glycemic load have been historically targeted as a goal of diabetes management, and thus low-carbohydrate diets have gained much attention [5]. However, by restricting a single nutrient- and carbohydrate-containing food group, such as whole grains, fruits and dairy may also be omitted, thereby leading to 
the exclusion of many micronutrients and dietary bioactive compounds shown to improve hyperglycemia $[6,7]$. This necessitates the examination of dietary patterns over nutrients.

While the role of dietary patterns has been associated with glycemic control and vascular complications of T1D in children and adolescents [8,9], only a few studies have reported the association of dietary patterns with glycemic control in adults. In a cross-sectional study in Chinese adults with T1D $(n=99)$, a higher intake of a dietary pattern containing high-fat cakes, beans and picked vegetables was positively associated with $\mathrm{HbA1c}$ and LDL-cholesterol when compared to those consuming a diet high in rice and eggs [10]. In a seven-year prospective cohort study in European adults with T1D $(n=1659)$, a lower intake of vegetable, protein and fiber was inversely associated with $\mathrm{HbA1c}$; this study did not report dietary patterns and micronutrient intakes [11]. In another prospective study with a five-year follow-up in T1D adults residing in Canada and the US $(n=532)$ undergoing intensive treatment from the Diabetes Control and Complications Trial (DCCT), inverse associations between $\mathrm{HbA} 1 \mathrm{c}$ and dietary carbohydrate, and positive associations with total fat, saturated fatty acids and mono-unsaturated fatty acids intake, were shown [12]. Again, dietary patterns were not reported in the DCCT report. Studies assessing dietary patterns and how they relate to glycemic control have been reported in type 2 diabetes: westernstyle dietary pattern and diets containing sweets and dairy were associated with higher $\mathrm{HbA1c}$ in a cross-sectional study in Mexico $(n=4838)$ [13]; dietary patterns characterized by "refined grains and meat" and "oil and salt" were positively associated with insulin resistance in a case-control study in China $(n=836)$ [14]; again, a western-style dietary pattern was associated with hyperglycemia in a cross-sectional study in Iran $(n=400)$ [15].

Habitual dietary intakes vary widely among populations and by geographical regions. Thus, we sought to examine how dietary patterns are associated with glycemic control in a US population with and without type 1 diabetes participating in the coronary artery calcification in type 1 diabetes (CACTI) study. We aim to contribute to the dearth of literature on the role of dietary patterns and macronutrients with glycemic control in adults with and without T1D. We have previously reported an inverse association between dietary fiber intake and $\mathrm{HbA} 1 \mathrm{c}$ in adults with and without T1D [16]. We extended this dietary investigation and sought to examine how dietary patterns, nutrients and food groups were associated with $\mathrm{HbA1c}$ in the same cohort.

\section{Materials and Methods}

Study participants: In this report we present data collected at baseline and at year 6 of the CACTI study as described previously [17]. All study participants provided informed consent and the study protocol was approved by the Colorado Multiple Institutional Review Board (ethics code 97-661). The study was registered at clinicaltrials.gov (NCT00005754).

Dietary intake: The dietary intakes of foods and nutrients were determined using a validated self-administered food-frequency questionnaire (Harvard, 1988) [18]. The procedures have been previously published in detail [17].

Cardiovascular risk factors: Baseline examinations were conducted between March 2000 and April 2002. Anthropometric measurements involved height, weight and waist circumference, and body mass index. Systolic blood pressure (SBP) and fifth-phase diastolic blood pressure (DBP) were measured during the rest state and an average of three measurements were reported. Participants also completed standardized questionnaires on medical history, current medication, insulin doses, physical activity (modifiable activity questionnaire) [19], alcohol and tobacco use and family medical history. Blood samples were collected in the $12 \mathrm{~h}$ fasting state for biochemical analyses (blood LDL- and HDL-cholesterol, triacylglycerol and HbA1c).

Statistical analysis: Baseline characteristics between men and women with type 1 diabetes and without diabetes were examined using a Student's $t$ test. A $\chi^{2}$ test for goodness of fit was used to determine if categorical risk factors differed between participants with and without diabetes. A Wilcoxon rank sum test was used to compare differences in 
continuous variables with skewed distributions. Factor analysis was used to formulate dietary patterns, and foods were considered to form part of the dietary patterns with a load factor greater than 0.4 . The varimax rotation was made to generate robust dietary patterns for interpretation. We only considered factors with the three largest eigenvalues for further analyses. Linear regression analysis was used to examine the associations of dietary patterns and macronutrients with baseline $\mathrm{HbA} 1 \mathrm{c}$, as well as with $\mathrm{HbA} 1 \mathrm{c}$ at the year 6 follow-up. Models were adjusted for relevant covariates as follows: model 1 (age, sex, BMI, and diabetes duration for T1D), model 2 (model $1+$ total calories, dietary carbohydrates, fats, proteins, and fiber) and model 3 (model $1+$ total calories and serum lipids). These models were stratified by diabetes as we observed significant interaction effects. In addition, longitudinal analyses were adjusted for baseline HbA1c, year 6 BMI and the duration of follow-up. We also examined the associations of food groups with $\mathrm{HbA} 1 \mathrm{c}$ at baseline and at the year 6 follow-up in a model adjusted for age, sex, BMI, total calories, and diabetes status; the year 6 model was further adjusted for baseline $\mathrm{HbA} 1 \mathrm{c}$, year $6 \mathrm{BMI}$ and duration of follow-up.

\section{Results}

\subsection{Baseline and Year 6 Features}

Table 1 shows the baseline characteristics of the cohort by diabetes status. Among the participants with T1D, we observed significantly younger age, a greater number of females, higher systolic but lower diastolic blood pressure, and better lipid profiles (lower LDL-C and triglycerides and higher HDL-C) when compared with non-diabetic controls. As expected, those with T1D had significantly higher $\mathrm{HbA1c}$ than the controls. While total calorie intake did not differ between groups, adults with T1D consumed significantly lower percentage of total calories as carbohydrates, but a higher percentage of calories as proteins, dietary fats, saturated fats as well as animal fats when compared to non-diabetic controls. No significant differences in BMI and physical activity levels were noted between groups (Table 1). At year 6 , among adults with T1D, the mean \pm SD for $\mathrm{HbA1c}$ was $8.1 \pm 1.6 \%$, BMI was $26.8 \pm 4.5 \mathrm{~kg} / \mathrm{m}^{2}$, SBP was $121 \pm 16 \mathrm{~mm} \mathrm{Hg}$, DBP was $78 \pm 12 \mathrm{~mm} \mathrm{Hg}$, LDL-C was $108 \pm 32 \mathrm{mg} / \mathrm{dL}$, HDL-C was $52 \pm 10 \mathrm{mg} / \mathrm{dL}$, and triacylglycerol was $102 \pm 52 \mathrm{mg} / \mathrm{dL}$. These values were not significantly different from baseline.

Table 1. Baseline characteristics of participants.

\begin{tabular}{|c|c|c|c|c|c|}
\hline \multirow[b]{3}{*}{ Variables } & \multicolumn{2}{|c|}{ Type 1 Diabetes } & \multicolumn{2}{|c|}{ Non-Diabetic Controls } & \multirow[b]{3}{*}{$p$ Value } \\
\hline & \multicolumn{2}{|c|}{$n=568$} & \multicolumn{2}{|c|}{$n=689$} & \\
\hline & Mean or $n$ & SD or $\% \S$ & Mean or $n$ & SD or $\% \S$ & \\
\hline Age (years) & 37 & 9 & 39 & 9 & $<0.0001$ \\
\hline Sex (female; $n$ ) & 316 & 56 & 346 & 50 & 0.031 \\
\hline Diabetes duration (years) & 23.5 & 8.9 & - & - & - \\
\hline HbA1c (\%) & 7.9 & 1.2 & 5.5 & 0.4 & $<0.0001$ \\
\hline HbA1c (met < 7\% goal) & 113 & 20 & $\mathrm{~N} / \mathrm{A}$ & $\mathrm{N} / \mathrm{A}$ & $\mathrm{N} / \mathrm{A}$ \\
\hline $\operatorname{BMI}\left(\mathrm{kg} / \mathrm{m}^{2}\right)$ & 26.2 & 4.3 & 26.2 & 5.0 & 0.929 \\
\hline SBP (mmHg) & 117 & 14 & 114 & 12 & $<0.0001$ \\
\hline $\mathrm{DBP}(\mathrm{mmHg})$ & 77 & 9 & 79 & 8 & 0.001 \\
\hline LDL-C (mg/dL) & 101 & 29 & 115 & 33 & $<0.0001$ \\
\hline HDL-C (mg/dL) & 56 & 16 & 50 & 14 & $<0.0001$ \\
\hline Triacylglycerol (mg/dL) & 93 & 54 & 132 & 103 & $<0.0001$ \\
\hline Dietary total calories (kcal/day) & 1766 & 613 & 1822 & 619 & 0.111 \\
\hline
\end{tabular}


Table 1. Cont.

\begin{tabular}{|c|c|c|c|c|c|}
\hline \multirow[b]{3}{*}{ Variables } & \multicolumn{2}{|c|}{ Type 1 Diabetes } & \multicolumn{2}{|c|}{ Non-Diabetic Controls } & \multirow[b]{3}{*}{$p$ Value } \\
\hline & \multicolumn{2}{|c|}{$n=568$} & \multicolumn{2}{|c|}{$n=689$} & \\
\hline & Mean or $n$ & SD or $\% \S$ & Mean or $n$ & SD or $\% \S$ & \\
\hline Dietary carbohydrates (\% kcal/day) & 45 & 9 & 48 & 9 & $<0.0001$ \\
\hline Dietary fats (\% kcal/day) & 35 & 7 & 33 & 7 & $<0.0001$ \\
\hline Dietary saturated fats (\% kcal/day) & 12.7 & 3.1 & 11.7 & 2.8 & $<0.0001$ \\
\hline Dietary proteins (\% kcal/day) & 19.7 & 3.6 & 18.5 & 3.9 & 0.0007 \\
\hline Dietary fiber (g/day) & 16.7 & 7.8 & 16.7 & 8.1 & 0.874 \\
\hline Dietary animal fats (g/day) & 40.7 & 20.1 & 38.1 & 18.6 & 0.0188 \\
\hline Dietary vegetable fats (g/day) & 28.5 & 13.8 & 28.2 & 14.1 & 0.683 \\
\hline Fruit, veggie, cereal, and meat pattern & 0.06 & 1.35 & -0.06 & 0.56 & 0.07 \\
\hline Baked desserts pattern & 0.01 & 1.18 & -0.006 & 0.85 & 0.77 \\
\hline Convenience foods and alcohol pattern & -0.04 & 0.86 & 0.03 & 1.11 & 0.22 \\
\hline Physical activity (KJ/week) & 6268 & 1121 & 6609 & 1098 & 0.21 \\
\hline
\end{tabular}

$\S$ Column percentage. $p<0.05$ in bold font. N/A, not applicable.

\subsection{Associations of Dietary Patterns and Nutrients with Glycemia at Cross-Sectional and} Longitudinal Time Points

Table 2 depicts the multivariate model examining the associations of dietary patterns and nutrients with $\mathrm{HbA} 1 \mathrm{c}$ at baseline and at year 6 of the study in models adjusted for age, sex, BMI, total calories, and nutrients, as well as blood lipids, stratified by diabetes. Among the dietary patterns identified in the cohort, the "fruit, veggie, cereal and meat" pattern and the "convenience food and alcohol" pattern were not associated with HbA1c at any time point in participants with and without T1D. On the other hand, the "baked desserts" pattern was positively associated with baseline HbA1c in the model adjusted for age, sex, and diabetes duration, as well as in the model further adjusted for total calories and blood lipids in the T1D group. This pattern tended to be positively associated when the model was further adjusted for the macronutrients. Similarly, the "baked desserts" pattern was positively associated with year $6 \mathrm{HbA} 1 \mathrm{c}$ in all models and revealed a borderline significant association in the model further adjusted for total calories and blood lipids in the T1D group. No such associations were noted in non-diabetic controls. Among the macronutrients, dietary carbohydrates and proteins, as a percentage of total calories, revealed a significant positive association with year $6 \mathrm{HbA} 1 \mathrm{c}$ in the T1D group in models adjusted for age, sex, BMI, diabetes duration, total calories, and blood lipids, but not in the model further adjusted for other macronutrients and fiber. No such associations were noted in non-diabetic controls. Additionally, dietary carbohydrates and proteins revealed no associations with baseline $\mathrm{HbA1c}$ in any model. While total dietary fats revealed no association with $\mathrm{HbA1c}$ at any time point in the T1D group, saturated fats, as a percentage of total calories, revealed a significant positive association with baseline, as well as year $6 \mathrm{HbA} 1 \mathrm{c}$ only in the model adjusted for age, sex, BMI, and diabetes duration in the T1D group. Finally, animal fats also showed a significant positive association with baseline $\mathrm{HbA} 1 \mathrm{c}$ in models adjusted for the aforementioned factors, as well as total calories and macronutrients. Vegetable fats revealed no significant associations with $\mathrm{HbA} 1 \mathrm{c}$ at any time point in either group. 
Table 2. Associations of dietary patterns and macronutrients with $\mathrm{HbA1c}$ in adults with and without type 1 diabetes (T1D).

\begin{tabular}{|c|c|c|c|c|c|c|c|c|}
\hline \multirow{3}{*}{$\begin{array}{c}\text { Dietary } \\
\text { Patterns/Nutrients } \\
\text { (Baseline) }\end{array}$} & \multicolumn{4}{|c|}{ HbA1c (Baseline) } & \multicolumn{4}{|c|}{ HbA1c (Year 6) } \\
\hline & \multirow{2}{*}{$\begin{array}{c}\begin{array}{c}\text { T1D } \\
(n=568)\end{array} \\
\beta \pm S E\end{array}$} & \multicolumn{3}{|c|}{$\begin{array}{c}\text { Non-Diabetic } \\
\text { Control } \\
(n=689)\end{array}$} & \multirow{2}{*}{$\begin{array}{c}\begin{array}{c}\text { T1D } \\
(n=452)\end{array} \\
\beta \pm S E\end{array}$} & \multicolumn{3}{|c|}{$\begin{array}{c}\text { Non-Diabetic } \\
\text { Control } \\
(n=538)\end{array}$} \\
\hline & & $p$ & $\beta \pm \mathrm{SE}$ & $p$ & & $p$ & $\beta \pm S E$ & $p$ \\
\hline \multicolumn{9}{|c|}{ Fruit, veggie, cereal, meat pattern } \\
\hline Model $1^{\mathrm{a}}$ & $0.06 \pm 0.04$ & 0.15 & $0.003 \pm 0.03$ & 0.91 & $0.03 \pm 0.04$ & 0.47 & $-0.005 \pm 0.05$ & 0.92 \\
\hline Model $2^{b}$ & $0.07 \pm 0.04$ & 0.10 & $0.016 \pm 0.03$ & 0.65 & $0.05 \pm 0.04$ & 0.19 & $-0.003 \pm 0.05$ & 0.94 \\
\hline Model $3^{c}$ & $0.03 \pm 0.04$ & 0.35 & $0.002 \pm 0.03$ & 0.94 & $0.02 \pm 0.03$ & 0.51 & $0.0002 \pm 0.05$ & 0.99 \\
\hline \multicolumn{9}{|c|}{ Baked desserts pattern } \\
\hline Model $1^{\mathrm{a}}$ & $0.11 \pm 0.05$ & 0.02 & $0.004 \pm 0.03$ & 0.96 & $0.12 \pm 0.06$ & 0.03 & $0.02 \pm 0.02$ & 0.32 \\
\hline Model $2^{b}$ & $0.08 \pm 0.05$ & 0.07 & $0.002 \pm 0.03$ & 0.98 & $0.11 \pm 0.06$ & 0.04 & $0.022 \pm 0.02$ & 0.37 \\
\hline Model $3^{c}$ & $0.11 \pm 0.04$ & 0.02 & $0.002 \pm 0.02$ & 0.89 & $0.11 \pm 0.06$ & 0.05 & $0.021 \pm 0.02$ & 0.41 \\
\hline \multicolumn{9}{|c|}{ Convenience foods and alcohol pattern } \\
\hline Model $1^{a}$ & $0.12 \pm 0.07$ & 0.09 & $0.002 \pm 0.05$ & 0.65 & $0.06 \pm 0.06$ & 0.35 & $-0.007 \pm 0.02$ & 0.73 \\
\hline Model $2^{b}$ & $0.13 \pm 0.07$ & 0.06 & $0.001 \pm 0.02$ & 0.47 & $0.08 \pm 0.06$ & 0.18 & $-0.008 \pm 0.02$ & 0.75 \\
\hline Model $3^{c}$ & $0.06 \pm 0.06$ & 0.34 & $0.008 \pm 0.02$ & 0.64 & $0.05 \pm 0.06$ & 0.41 & $-0.011 \pm 0.02$ & 0.63 \\
\hline \multicolumn{9}{|c|}{ Carbohydrates (\% kcal) } \\
\hline Model $1^{a}$ & $0.006 \pm 0.005$ & 0.28 & $0.002 \pm 0.001$ & 0.18 & $0.013 \pm 0.005$ & 0.02 & $0.001 \pm 0.002$ & 0.46 \\
\hline Model $2^{b}$ & $0.017 \pm 0.014$ & 0.22 & $0.002 \pm 0.003$ & 0.56 & $0.002 \pm 0.014$ & 0.88 & $0.005 \pm 0.003$ & 0.27 \\
\hline Model $3^{c}$ & $0.007 \pm 0.005$ & 0.21 & $0.002 \pm 0.001$ & 0.23 & $0.014 \pm 0.005$ & 0.02 & $0.001 \pm 0.002$ & 0.47 \\
\hline \multicolumn{9}{|l|}{ Proteins (\%kcal) } \\
\hline Model $1^{a}$ & $0.01 \pm 0.02$ & 0.47 & $0.003 \pm 0.004$ & 0.40 & $0.03 \pm 0.01$ & 0.02 & $0.009 \pm 0.005$ & 0.86 \\
\hline Model $2^{b}$ & $0.03 \pm 0.02$ & 0.15 & $0.006 \pm 0.005$ & 0.23 & $0.03 \pm 0.02$ & 0.08 & $0.007 \pm 0.004$ & 0.66 \\
\hline Model $3^{c}$ & $0.02 \pm 0.01$ & 0.14 & $0.003 \pm 0.002$ & 0.42 & $0.03 \pm 0.01$ & 0.008 & $0.007 \pm 0.003$ & 0.86 \\
\hline \multicolumn{9}{|l|}{ Total Fats (\% kcal) } \\
\hline Model $1^{a}$ & $0.010 \pm 0.007$ & 0.17 & $0.003 \pm 0.002$ & 0.07 & $0.013 \pm 0.007$ & 0.08 & $0.006 \pm 0.003$ & 0.06 \\
\hline Model $2^{b}$ & $0.019 \pm 0.015$ & 0.19 & $0.009 \pm 0.004$ & 0.82 & $0.011 \pm 0.15$ & 0.43 & $0.013 \pm 0.005$ & 0.02 \\
\hline Model 3 ${ }^{c}$ & $0.008 \pm 0.007$ & 0.21 & $0.003 \pm 0.002$ & 0.11 & $0.013 \pm 0.007$ & 0.07 & $0.006 \pm 0.003$ & 0.06 \\
\hline \multicolumn{9}{|c|}{ Saturated fats $(\% \mathrm{kcal})$} \\
\hline Model $1^{a}$ & $0.015 \pm 0.002$ & 0.01 & $0.001 \pm 0.002$ & 0.12 & $0.018 \pm 0.007$ & 0.003 & $0.002 \pm 0.001$ & 0.06 \\
\hline Model $2^{b}$ & $0.012 \pm 0.015$ & 0.09 & $0.009 \pm 0.004$ & 0.82 & $0.015 \pm 0.04$ & 0.22 & $0.014 \pm 0.003$ & 0.02 \\
\hline Model $3^{c}$ & $0.008 \pm 0.003$ & 0.09 & $0.002 \pm 0.002$ & 0.11 & $0.013 \pm 0.007$ & 0.13 & $0.010 \pm 0.003$ & 0.05 \\
\hline \multicolumn{9}{|l|}{ Animal fats } \\
\hline Model $1^{\mathrm{a}}$ & $0.008 \pm 0.002$ & 0.002 & $0.002 \pm 0.002$ & 0.11 & $0.004 \pm 0.002$ & 0.11 & $0.007 \pm 0.02$ & 0.88 \\
\hline Model $2^{b}$ & $0.009 \pm 0.003$ & 0.006 & $0.001 \pm 0.001$ & 0.17 & $0.006 \pm 0.007$ & 0.24 & $0.001 \pm 0.01$ & 0.92 \\
\hline Model $3^{c}$ & $0.006 \pm 0.003$ & 0.07 & $0.002 \pm 0.001$ & 0.06 & $0.004 \pm 0.003$ & 0.27 & $0.011 \pm 0.01$ & 0.44 \\
\hline \multicolumn{9}{|l|}{ Vegetable fats } \\
\hline Model $1^{\mathrm{a}}$ & $0.005 \pm 0.003$ & 0.15 & $0.003 \pm 0.001$ & 0.61 & $0.004 \pm 0.003$ & 0.19 & $0.003 \pm 0.002$ & 0.74 \\
\hline Model $2^{b}$ & $0.008 \pm 0.003$ & 0.84 & $0.002 \pm 0.001$ & 0.64 & $0.007 \pm 0.006$ & 0.26 & $0.008 \pm 0.001$ & 0.99 \\
\hline Model $3^{c}$ & $0.004 \pm 0.003$ & 0.91 & $0.003 \pm 0.001$ & 0.65 & $0.005 \pm 0.004$ & 0.44 & $0.003 \pm 0.002$ & 0.11 \\
\hline
\end{tabular}

${ }^{a}$ Model adjusted for age, sex, BMI, and diabetes duration for T1D; age, sex and BMI for non-diabetic control; year 6 model also adjusted for baseline $\mathrm{HbA1c}$, year $6 \mathrm{BMI}$ and duration of follow-up. ${ }^{\mathrm{b}}$ Model $1+$ total calories, dietary carbohydrates, fats, proteins and fiber (excluding relevant covariates when these are independent variables in the model). ${ }^{c}$ Model $1+$ total calories, serum total cholesterol and triglycerides T1D: type 1 diabetes. $p<0.05$ are in bold font. 


\subsection{Associations of Food Groups with Glycemia at Cross-Sectional and Longitudinal Time Points}

Table 3 depicts the multivariate model examining the associations of dietary food groups with $\mathrm{HbA} 1 \mathrm{c}$ at baseline and at year 6 of the study in a model adjusted for age, sex, BMI, total calories, and diabetes status. Broadly, no significant associations were noted in the fruit and vegetable groups, except for an inverse association of dark green vegetables with baseline $\mathrm{HbA} 1 \mathrm{c}$ and of tomatoes with year $6 \mathrm{HbA} 1 \mathrm{c}$. No associations were noted for dairy, legumes, nuts, cereals, and protein groups. Interestingly, in the beverage group, lowcalorie/no-calorie beverages were positively associated with $\mathrm{HbA1c}$ at both time points. As constituents of the "baked desserts" pattern, commercial and home-made cookies, candies, cakes, and pies as a food group also revealed a significant positive association with $\mathrm{HbA1c}$ at both time points.

Table 3. Associations of food groups with HbA1c in adults with and without T1D.

\begin{tabular}{|c|c|c|c|c|}
\hline \multirow[t]{2}{*}{ Food Groups (Baseline) } & \multicolumn{2}{|c|}{ HbA1c (Baseline) } & \multicolumn{2}{|c|}{ HbA1c (Year 6) } \\
\hline & $\beta \pm S E$ & $p$ & $\beta \pm S E$ & $p$ \\
\hline Whole fruits & $0.001 \pm 0.022$ & 0.96 & $0.02 \pm 0.01$ & 0.19 \\
\hline Fruit juice & $0.06 \pm 0.04$ & 0.14 & $0.06 \pm 0.04$ & 0.98 \\
\hline Tomatoes & $-0.04 \pm 0.07$ & 0.61 & $-0.12 \pm 0.04$ & 0.009 \\
\hline Dark green vegetables & $-0.04 \pm 0.02$ & 0.04 & $-0.02 \pm 0.02$ & 0.43 \\
\hline Starchy vegetables & $-0.07 \pm 0.06$ & 0.31 & $-0.05 \pm 0.04$ & 0.19 \\
\hline Orange/red vegetables & $0.05 \pm 0.06$ & 0.52 & $0.07 \pm 0.03$ & 0.85 \\
\hline Other vegetables & $0.03 \pm 0.04$ & 0.51 & $0.05 \pm 0.02$ & 0.07 \\
\hline Low fat dairy & $0.08 \pm 0.06$ & 0.17 & $-0.02 \pm 0.04$ & 0.64 \\
\hline Other dairy & $0.03 \pm 0.01$ & 0.09 & $-0.03 \pm 0.02$ & 0.75 \\
\hline Legumes & $-0.02 \pm 0.06$ & 0.67 & $0.11 \pm 0.06$ & 0.86 \\
\hline Nuts & $0.10 \pm 0.05$ & 0.08 & $0.03 \pm 0.05$ & 0.40 \\
\hline Eggs & $0.11 \pm 0.05$ & 0.99 & $0.03 \pm 0.04$ & 0.54 \\
\hline Red meat & $0.05 \pm 0.03$ & 0.10 & $0.06 \pm 0.03$ & 0.66 \\
\hline Processed meat & $0.03 \pm 0.04$ & 0.37 & $0.02 \pm 0.01$ & 0.27 \\
\hline Fish, low cholesterol & $0.09 \pm 0.05$ & 0.79 & $0.05 \pm 0.04$ & 0.33 \\
\hline Fish, high cholesterol & $0.11 \pm 0.05$ & 0.15 & $0.13 \pm 0.05$ & 0.15 \\
\hline Chicken/Turkey & $0.03 \pm 0.04$ & 0.14 & $0.05 \pm 0.04$ & 0.81 \\
\hline Pizza & $0.12 \pm 0.05$ & 0.97 & $0.11 \pm 0.05$ & 0.86 \\
\hline Salty snacks & $0.02 \pm 0.03$ & 0.18 & $0.04 \pm 0.03$ & 0.17 \\
\hline Low-calorie/no-calorie beverages & $0.11 \pm 0.03$ & 0.002 & $0.41 \pm 0.06$ & $<0.001$ \\
\hline SSB & $0.02 \pm 0.01$ & 0.47 & $0.07 \pm 0.02$ & 0.67 \\
\hline Tea & $0.02 \pm 0.03$ & 0.51 & $0.11 \pm 0.04$ & 0.06 \\
\hline Coffee & $-0.02 \pm 0.02$ & 0.33 & $-0.03 \pm 0.04$ & 0.47 \\
\hline Wine & $-0.04 \pm 0.04$ & 0.35 & $0.05 \pm 0.04$ & 0.92 \\
\hline Beer & $-0.06 \pm 0.05$ & 0.47 & $0.19 \pm 0.05$ & 0.79 \\
\hline Liquor & $0.17 \pm 0.10$ & 0.08 & $0.11 \pm 0.05$ & 0.52 \\
\hline $\begin{array}{l}\text { Candy, cookies, pies, cakes, rolls } \\
\text { (homemade and commercial) }\end{array}$ & $0.05 \pm 0.01$ & 0.001 & $0.03 \pm 0.01$ & 0.04 \\
\hline Cold breakfast cereal & $0.09 \pm 0.05$ & 0.32 & $0.10 \pm 0.06$ & 0.06 \\
\hline Cooked breakfast cereal & $0.04 \pm 0.03$ & 0.42 & $0.04 \pm 0.03$ & 0.21 \\
\hline Refined grains & $0.05 \pm 0.03$ & 0.15 & $0.11 \pm 0.03$ & 0.54 \\
\hline Whole grains & $0.02 \pm 0.01$ & 0.78 & $-0.06 \pm 0.03$ & 0.03 \\
\hline
\end{tabular}

Adjusted for age, sex, BMI, total calories and diabetes status; year 6 model also adjusted for baseline HbA1c, year 6 BMI and duration of follow-up; SSB: sugar-sweetened beverage; T1D: type 1 diabetes. $p<0.05$ are in bold font. 


\section{Discussion}

We report the significant positive association of a dietary pattern consisting mainly of baked desserts, such as candies, pies, cookies, and cakes, with $\mathrm{HbA} 1 \mathrm{c}$ at baseline and at year 6 of our longitudinal study in adults with T1D. This positive association remained significant in models adjusted for age, sex, BMI, diabetes duration, total calories, and/or blood lipids (serum cholesterol and triglycerides). To our knowledge, no previous study has reported such a consistent association between the habitual intake of baked goods and glycemic control in T1D adults. Among the commonly consumed food groups, as revealed in a meta-analysis of prospective studies $(n=88)$, red and processed meats and sugar-sweetened beverages (SSB) were associated with increased risks of type 2 diabetes. The study examined this association among 12 food groups but did not address baked desserts or those containing added fats and sugars, except SSB [20]. A baked desserts diet pattern is typically high in refined grains, added sugars, especially corn syrup, fat, and sodium, and low in fibers that have been associated with increased risks of diabetes [21,22]. Baked desserts are also high in hydrogenated fats, which is an important source of trans fats shown to increase diabetes and CVD risks [23-26]. On the other hand, we observed no association of a healthier dietary pattern characterized by fruits, vegetables, cereals and meats, or a diet consisting of convenience foods and alcohol, with $\mathrm{HbA} 1 \mathrm{c}$ in these adults, quite likely due to the foods in these diet patterns not significantly adding to or lowering the glycemic burden. These data show that in T1D adults, impaired glycemic control may be predicted by concentrated sources of sugars and fats, such as those in baked desserts, even if consuming lower dietary total carbohydrates than those without diabetes and following adjustment for total calories.

We also observed a positive association of saturated fats and animal fats with $\mathrm{HbA} 1 \mathrm{c}$ at baseline and/or at year 6 of the study in adults with T1D. Reports from some prospective studies in T1D adults, such as the EURODIAB Prospective Complication study with a seven-year follow-up ( $n=1102)$ [27], as well as the DCCT trial with a five-year follow-up, reveal a habitual dietary consumption that is high in total and saturated fats, but low in carbohydrates and fiber. In addition, the DCCT trial revealed this atherogenic diet pattern to be positively associated with $\mathrm{HbA} 1 \mathrm{c}$ in adults undergoing intensive treatment to achieve optimal glycemic control [12]. Similar trends in the habitual consumption of a high-fat diet have also been observed in children with T1D [28]. This high-fat diet pattern may be the result of lowering dietary sources of carbohydrates that directly add to the glycemic load, and increasing animal-based food groups high in protein and saturated fats that often add more palatability and satiety to the diet. Consequently, we also observed dietary protein intake to be positively associated with $\mathrm{HbA1c}$ at year 6 of the study in adjusted models. The higher $\mathrm{HbA1c}$ concentrations in association with higher saturated fat intakes may also be explained by the detrimental effects of saturated fats on insulin signaling. High-fat meals impair insulin signaling, which results in a transient increase in insulin resistance in mechanistic studies [29]. A study by Rosenfalck et al. suggested that a low-fat diet reduces basal free fatty acid concentrations and improves peripheral insulin sensitivity in a clinical study of T1D adults [30]. Based on these observations, the dietary management of T1D must aim to reduce saturated fat and animal fat intake to improve glycemic control and prevent CVD complications.

Our observations on the inverse associations of individual fruits and vegetables, such as tomatoes and dark green leafy vegetables, with $\mathrm{HbA} 1 \mathrm{c}$ conform to several observational studies on the protective associations of fruits and/or vegetables against type 2 diabetes [31-33]. These colorful fruits and vegetables are typically rich in carotenoids, and serum carotenoids have been inversely associated with poor glycemic control in adults [34,35]. In animal models of diabetes, the oral administration of lycopene ameliorated diabetes-related and oxidative stress markers [36,37]. However, such reports are scarce in adults with T1D, a gap which is addressed by our study. These findings warrant further attention in clinical studies involving the supplementation of fruits and vegetables or their bioactive compounds in diabetes management. We also observed a consistent 
positive association of the habitual intake of low-calorie beverages with $\mathrm{HbA} 1 \mathrm{c}$ at baseline, as well as at year 6 of the study in T1D adults. As a substitute for plain water and sugarsweetened beverages, low-calorie and no-calorie beverage consumption is a palatable and perceivably healthy option. However, the evidence supporting the risk to benefit ratio of regularly consuming these beverages is quite mixed [38], and data have shown some low-calorie sweeteners can increase body weight comparable to sucrose in adults with overweight or obesity [39], as well as higher energy intake in youths with type 2 diabetes, making them prone to obesity and poor glycemic control [40]. Thus, caution must be exercised in their regular consumption in T1D management.

Our study has some limitations. First, dietary data at baseline from the FFQ relied on a retrospective self-report which may be prone to recall bias. Additionally, our current analysis did not involve dietary exposures at year 6 of the study. Second, these observed associations cannot be generalized to adults without T1D and with multiple comorbidities. Third, our baseline for data collection on dietary and nutrient intakes was more than a decade earlier, and this may cause some discrepancies with the dietary pattens of adults in the current timeframe. However, these dietary patterns are similar to the US dietary intakes evaluated over 17 years, revealing a persistent high intake of saturated fats and low-quality carbohydrates [41]. Additionally, due to the smaller sample size at year 6 compared to the baseline, due to follow-up loss of participants, the results could have been driven towards null findings. Fourth, we did not adjust for any new glucose control therapies during the six-year period that may have affected some of the null findings at year 6. Finally, we did not measure food-specific biomarkers, such as blood levels of trans fatty acids or polyphenols, to further validate the self-reported FFQ exposure data.

In conclusion, our findings identify a dietary pattern containing increasing amounts of baked desserts to be associated with increasing $\mathrm{HbA1}$ c levels at baseline, as well with $\mathrm{HbA1c}$ after six years of follow-up in adults with T1D. Baseline dietary saturated and animal fats also revealed similar associations. Among the food groups, the positive association of low-/no-calorie beverages adds to the lack of data on their cardiometabolic effects in diabetes in adults. These data provide evidence for limiting baked desserts, saturated and animal fats, as well as low-/no-calorie sweeteners, and increasing the consumption of colorful fruits and vegetables, in the medical nutrition therapy for glycemic control in T1D management.

Author Contributions: A.B., A.C.A. and J.K.S.-B. contributed to the conception and design of the study, analysis, and interpretation of the data and drafted the manuscript. All authors have read and agreed to the published version of the manuscript and agreed to be fully accountable for ensuring the integrity and accuracy of the work.

Funding: Support for this study was provided by the National Institutes of Health National Heart, Lung and Blood Institute grants R01 HL61753, R01 HL079611 and R01 HL113029, American Diabetes Association grant 7-06-CVD-28, American Diabetes Association Grant 7-13-CD-10 (Snell-Bergeon), American Diabetes Association Grant 7-13-CE-02 (Alman), and Diabetes Endocrinology Research Center Clinical Investigation Core P30 DK57516. The study was performed at the Adult General Clinical Research Center at the University of Colorado Denver Anschutz Medical Center supported by the NIH M01 RR000051 and NIH/NCATS Colorado CTSA Grant Number UL1TR002535, the Barbara Davis Center for Childhood Diabetes in Denver and at Colorado Heart Imaging Center in Denver, CO, USA. In addition, support for statistical analyses for the current report was provided by the Dean's Faculty Development award (Basu) at the School of Integrated Health Sciences at UNLV.

Institutional Review Board Statement: The study protocol was approved by the Colorado Multiple Institutional Review Board.

Informed Consent Statement: Informed consent was obtained from all subjects involved in the study.

Data Availability Statement: The datasets analyzed in the current study are not publicly available due to ethical reasons and because our participants only gave their consent for the use of their data by the original team of investigators.

Conflicts of Interest: The authors declare no conflict of interest. 


\section{References}

1. Menke, A.; Casagrande, S.; Geiss, L.; Cowie, C.C. Prevalence of and Trends in Diabetes among Adults in the United States, 1988-2012. JAMA 2015, 314, 1021-1029. [CrossRef] [PubMed]

2. Lind, M.; Svensson, A.M.; Kosiborod, M.; Gudbjornsdottir, S.; Pivodic, A.; Wedel, H.; Dahlqvist, S.; Clements, M.; Rosengren, A. Glycemic control and excess mortality in type 1 diabetes. N. Engl. J. Med. 2014, 371, 1972-1982. [CrossRef] [PubMed]

3. American Diabetes Association. 5. Lifestyle Management: Standards of Medical Care in Diabetes-2019. Diabetes Care 2019, 42, S46-S60. [CrossRef] [PubMed]

4. $\quad$ Evert, A.B.; Dennison, M.; Gardner, C.D.; Garvey, W.T.; Lau, K.H.K.; MacLeod, J.; Mitri, J.; Pereira, R.F.; Rawlings, K.; Robinson, S.; et al. Nutrition Therapy for Adults With Diabetes or Prediabetes: A Consensus Report. Diabetes Care 2019, 42, 731-754. [CrossRef] [PubMed]

5. Lennerz, B.S.; Koutnik, A.P.; Azova, S.; Wolfsdorf, J.I.; Ludwig, D.S. Carbohydrate restriction for diabetes: Rediscovering centuries-old wisdom. J. Clin. Investig. 2021, 131. [CrossRef] [PubMed]

6. Wedick, N.M.; Pan, A.; Cassidy, A.; Rimm, E.B.; Sampson, L.; Rosner, B.; Willett, W.; Hu, F.B.; Sun, Q.; van Dam, R.M. Dietary flavonoid intakes and risk of type 2 diabetes in US men and women. Am. J. Clin. Nutr. 2012, 95, 925-933. [CrossRef]

7. Aune, D. Plant Foods, Antioxidant Biomarkers, and the Risk of Cardiovascular Disease, Cancer, and Mortality: A Review of the Evidence. Adv. Nutr. 2019, 10, S404-S421. [CrossRef]

8. Nansel, T.R.; Lipsky, L.M.; Liu, A. Greater diet quality is associated with more optimal glycemic control in a longitudinal study of youth with type 1 diabetes. Am. J. Clin. Nutr. 2016, 104, 81-87. [CrossRef]

9. Seckold, R.; Howley, P.; King, B.R.; Bell, K.; Smith, A.; Smart, C.E. Dietary intake and eating patterns of young children with type 1 diabetes achieving glycemic targets. BMJ Open Diabetes Res. Care 2019, 7, e000663. [CrossRef] [PubMed]

10. Jaacks, L.M.; Crandell, J.; Mendez, M.A.; Lamichhane, A.P.; Liu, W.; Ji, L.; Du, S.; Rosamond, W.; Popkin, B.M.; Mayer-Davis, E.J. Dietary patterns associated with $\mathrm{HbA1c}$ and LDL cholesterol among individuals with type 1 diabetes in China. J. Diabetes Its Complicat. 2015, 29, 343-349. [CrossRef] [PubMed]

11. Balk, S.N.; Schoenaker, D.A.; Mishra, G.D.; Toeller, M.; Chaturvedi, N.; Fuller, J.H.; Soedamah-Muthu, S.S. Association of diet and lifestyle with glycated haemoglobin in type 1 diabetes participants in the EURODIAB prospective complications study. Eur. J. Clin. Nutr. 2016, 70, 229-236. [CrossRef] [PubMed]

12. Delahanty, L.M.; Nathan, D.M.; Lachin, J.M.; Hu, F.B.; Cleary, P.A.; Ziegler, G.K.; Wylie-Rosett, J.; Wexler, D.J. Association of diet with glycated hemoglobin during intensive treatment of type 1 diabetes in the Diabetes Control and Complications Trial. Am. J. Clin. Nutr. 2009, 89, 518-524. [CrossRef] [PubMed]

13. Martínez, M.L.R.; Gómez-Díaz, R.A.; González, A.L.V.; González, R.M.; Becerra, M.C.S.; Rio, S.; Cruz, M.; Wacher-Rodarte, N.H.; Pacheco, R.A.R.; Aburto, V.H.B. Association between glycemic control and dietary patterns in patients with type 2 diabetes in a Mexican institute. Nutrition 2020, 78, 110901. [CrossRef] [PubMed]

14. Cai, J.; Nuli, R.; Zhang, Y.; Zhang, Y.; Abudusemaiti, M.; Kadeer, A.; Tian, X.; Xiao, H. Association of Dietary Patterns with Type 2 Diabetes Mellitus among Middle-Aged Adults in Uygur Population of Xinjiang Region. J. Nutr. Sci. Vitaminol. 2019, 65, 362-374. [CrossRef]

15. Darani Zad, N.; Mohd Yusof, R.; Esmaili, H.; Jamaluddin, R.; Mohseni, F. Association of dietary pattern with biochemical blood profiles and bodyweight among adults with Type 2 diabetes mellitus in Tehran, Iran. J. Diabetes Metab. Disord. $2015,14,28$. [CrossRef] [PubMed]

16. Basu, A.; Alman, A.C.; Snell-Bergeon, J.K. Dietary fiber intake and glycemic control: Coronary artery calcification in type 1 diabetes (CACTI) study. Nutr. J. 2019, 18, 23. [CrossRef]

17. Snell-Bergeon, J.K.; Chartier-Logan, C.; Maahs, D.M.; Ogden, L.G.; Hokanson, J.E.; Kinney, G.L.; Eckel, R.H.; Ehrlich, J.; Rewers, M. Adults with type 1 diabetes eat a high-fat atherogenic diet that is associated with coronary artery calcium. Diabetologia 2009, 52, 801-809. [CrossRef] [PubMed]

18. Rimm, E.B.; Giovannucci, E.L.; Stampfer, M.J.; Colditz, G.A.; Litin, L.B.; Willett, W.C. Reproducibility and validity of an expanded self-administered semiquantitative food frequency questionnaire among male health professionals. Am. J. Epidemiol. 1992, 135, 1114-1126, discussion 1127-1136. [CrossRef] [PubMed]

19. Kriska, A.M.; Knowler, W.C.; LaPorte, R.E.; Drash, A.L.; Wing, R.R.; Blair, S.N.; Bennett, P.H.; Kuller, L.H. Development of questionnaire to examine relationship of physical activity and diabetes in Pima Indians. Diabetes Care 1990, 13, 401-411. [CrossRef] [PubMed]

20. Schwingshackl, L.; Hoffmann, G.; Lampousi, A.M.; Knüppel, S.; Iqbal, K.; Schwedhelm, C.; Bechthold, A.; Schlesinger, S.; Boeing, H. Food groups and risk of type 2 diabetes mellitus: A systematic review and meta-analysis of prospective studies. Eur. J. Epidemiol. 2017, 32, 363-375. [CrossRef]

21. Gross, L.S.; Li, L.; Ford, E.S.; Liu, S. Increased consumption of refined carbohydrates and the epidemic of type 2 diabetes in the United States: An ecologic assessment. Am. J. Clin. Nutr. 2004, 79, 774-779. [CrossRef] [PubMed]

22. Goran, M.I.; Ulijaszek, S.J.; Ventura, E.E. High fructose corn syrup and diabetes prevalence: A global perspective. Glob. Public Health 2013, 8, 55-64. [CrossRef] [PubMed]

23. Mozaffarian, D.; Aro, A.; Willett, W.C. Health effects of trans-fatty acids: Experimental and observational evidence. Eur. J. Clin. Nutr. 2009, 63 (Suppl. 2), S5-S21. [CrossRef] 
24. Islam, M.A.; Amin, M.N.; Siddiqui, S.A.; Hossain, M.P.; Sultana, F.; Kabir, M.R. Trans fatty acids and lipid profile: A serious risk factor to cardiovascular disease, cancer and diabetes. Diabetes Metab. Syndr. 2019, 13, 1643-1647. [CrossRef]

25. Gonçalves, R.V.; Santos, J.D.B.; Silva, N.S.; Guillocheau, E.; Silva, R.E.; Souza-Silva, T.G.; Oliveira, R.F.; Santos, E.C.; Novaes, R.D. Trans-fatty acids aggravate anabolic steroid-induced metabolic disturbances and differential gene expression in muscle, pancreas and adipose tissue. Life Sci. 2019, 232, 116603. [CrossRef]

26. Risérus, U. Trans fatty acids and insulin resistance. Atheroscler. Suppl. 2006, 7, 37-39. [CrossRef]

27. Soedamah-Muthu, S.S.; Chaturvedi, N.; Fuller, J.H.; Toeller, M. Do European people with type 1 diabetes consume a high atherogenic diet? 7-year follow-up of the EURODIAB Prospective Complications Study. Eur. J. Nutr. 2013, 52, 1701-1710. [CrossRef] [PubMed]

28. Mehta, S.N.; Volkening, L.K.; Quinn, N.; Laffel, L.M. Intensively managed young children with type 1 diabetes consume high-fat, low-fiber diets similar to age-matched controls. Nutr. Res. 2014, 34, 428-435. [CrossRef] [PubMed]

29. Savage, D.B.; Petersen, K.F.; Shulman, G.I. Disordered lipid metabolism and the pathogenesis of insulin resistance. Physiol. Rev. 2007, 87, 507-520. [CrossRef] [PubMed]

30. Rosenfalck, A.M.; Almdal, T.; Viggers, L.; Madsbad, S.; Hilsted, J. A low-fat diet improves peripheral insulin sensitivity in patients with Type 1 diabetes. Diabet. Med. J. Br. Diabet. Assoc. 2006, 23, 384-392. [CrossRef]

31. Jannasch, F.; Kroger, J.; Schulze, M.B. Dietary Patterns and Type 2 Diabetes: A Systematic Literature Review and Meta-Analysis of Prospective Studies. J. Nutr. 2017, 147, 1174-1182. [CrossRef] [PubMed]

32. Carter, P.; Gray, L.J.; Troughton, J.; Khunti, K.; Davies, M.J. Fruit and vegetable intake and incidence of type 2 diabetes mellitus: Systematic review and meta-analysis. BMJ 2010, 341, c4229. [CrossRef] [PubMed]

33. Villegas, R.; Shu, X.O.; Gao, Y.T.; Yang, G.; Elasy, T.; Li, H.; Zheng, W. Vegetable but not fruit consumption reduces the risk of type 2 diabetes in Chinese women. J. Nutr. 2008, 138, 574-580. [CrossRef] [PubMed]

34. Coyne, T.; Ibiebele, T.I.; Baade, P.D.; Dobson, A.; McClintock, C.; Dunn, S.; Leonard, D.; Shaw, J. Diabetes mellitus and serum carotenoids: Findings of a population-based study in Queensland, Australia. Am. J. Clin. Nutr. 2005, 82, 685-693. [CrossRef] [PubMed]

35. Ford, E.S.; Will, J.C.; Bowman, B.A.; Narayan, K.M. Diabetes mellitus and serum carotenoids: Findings from the Third National Health and Nutrition Examination Survey. Am. J. Epidemiol. 1999, 149, 168-176. [CrossRef]

36. Yin, Y.; Zheng, Z.; Jiang, Z. Effects of lycopene on metabolism of glycolipid in type 2 diabetic rats. Biomed. Pharmacother. 2019, 109, 2070-2077. [CrossRef]

37. Zheng, Z.; Yin, Y.; Lu, R.; Jiang, Z. Lycopene Ameliorated Oxidative Stress and Inflammation in Type 2 Diabetic Rats. J. Food Sci. 2019, 84, 1194-1200. [CrossRef] [PubMed]

38. Fowler, S.P.G. Low-calorie sweetener use and energy balance: Results from experimental studies in animals, and large-scale prospective studies in humans. Physiol. Behav. 2016, 164, 517-523. [CrossRef] [PubMed]

39. Higgins, K.A.; Mattes, R.D. A randomized controlled trial contrasting the effects of 4 low-calorie sweeteners and sucrose on body weight in adults with overweight or obesity. Am. J. Clin. Nutr. 2019, 109, 1288-1301. [CrossRef]

40. Sylvetsky, A.C.; Chandran, A.; Talegawkar, S.A.; Welsh, J.A.; Drews, K.; El Ghormli, L. Consumption of Beverages Containing Low-Calorie Sweeteners, Diet, and Cardiometabolic Health in Youth With Type 2 Diabetes. J. Acad. Nutr. Diet. 2020, 120, 1348-1358.e1346. [CrossRef] [PubMed]

41. Shan, Z.; Rehm, C.D.; Rogers, G.; Ruan, M.; Wang, D.D.; Hu, F.B.; Mozaffarian, D.; Zhang, F.F.; Bhupathiraju, S.N. Trends in Dietary Carbohydrate, Protein, and Fat Intake and Diet Quality among US Adults, 1999-2016. Jama 2019, 322, 1178-1187. [CrossRef] [PubMed] 